\title{
Helping Me Helping You: Designing to Influence Health Behaviour through Social Connections
}

\author{
Noreen Kamal $^{1}$, Sidney Fels ${ }^{1}$, Joanna McGrenere ${ }^{2}$, and Kara Nance ${ }^{3}$ \\ ${ }^{1}$ Electrical \& Computer Engineering, University of British Columbia, Vancouver, BC, Canada \\ ${ }^{2}$ Department of Computer Science, University of British Columbia, Vancouver, BC, Canada \\ ${ }^{3}$ How To Be Healthy MD, Rolling Meadows, IL, USA \\ \{noreenk, ssfels\}@ece.ubc.ca, joanna@cs.ubc.ca, \\ karajnance@gmail.com
}

\begin{abstract}
Of key importance to avoiding significant health problems such as cardiac disease and stroke is eating nutritious foods and leading an active lifestyle. However, leading a healthy lifestyle remains elusive and obesity continues to increase in North America. We investigate how online social networks (OSN) can change health behaviour by blending theories from health behaviour and participation in OSNs. We designed, prototyped and evaluated an OSN, called VivoSpace, using factors derived from the blend of theoretical models with the intention to change health behaviour. Our results from field studies with 35 participants from two clinical and one non-clinical social network groups revealed that designing these factors into the online social network lead to positive health behaviour change, namely, improved diet for the clinical group. The use of theoretical models in the evaluation provided a means to understand how the design can be improved to see further health behaviour change.
\end{abstract}

Keywords: Health, behaviour change, social networks, diet, physical activity.

\section{Introduction}

The importance of a nutritious diet and an active lifestyle has been found to be central to a healthy population, which leads to lower healthcare costs for a nation and a better quality of life for its citizens. Specifically, a healthy diet and physical activity can reduce advancement of (and prevent occurrence of) chronic diseases [2], prevent vascular diseases such as cardiac disease and stroke [22,7,15], and result in overall better health [31]. Despite greater medical and scientific knowledge, North Americans continue to be more obese due to poor diet and a sedentary lifestyle. We address this problem through the design and evaluation of an online social network (OSN), grounded in theoretical models, to improve nutrition and increase physical activity.

In addition to diet and physical activity, a significant factor in health outcomes is one's close and distant social networks $[8,23]$. Social supports can promote better health by providing a sense of belonging and building self-efficacy [6]. Social technology has been shown to increase social support for individuals afflicted with a 
particular condition, such as ACL (Anterior Cruciate Ligament) [25], ALS (Amyotrophic Lateral Sclerosis) [13] and menopause [36]. Furthermore, the social dynamics for peer involvement in weight management include supportive relations and passive involvement (such as social norms), and observed patterns of interaction such as (un)disclosure [24]. Studies have realized the benefits of social connection by designing technologies for health and weight management, which we review in detail in the Related Work section.

Recently, social connection through websites and other web enabled technology have had an explosion of engagement and use, namely in use of OSN services such as Facebook®. We leverage this engagement as a means to build social support in the design of our OSN for health behaviour change. We also take heed of studies that have shown we need to be cautious in using large OSN services such as Facebook® for our health needs, as issues of sharing private health information on such a large social network service does not make sense [29,33]. We build on these works by designing an OSN for small social network groups rather than using existing OSN such as Facebook®. This is done to allow users to share their nutrition and physical activity data with individuals from a known social network group rather than a large social network that would broadcast their data to a diverse range of individuals known from various sources. A small social network group allows users to have control over who sees the information that is disclosed.

The main contribution of this work is to apply two theories to the design, prototyping and evaluation of an OSN, VivoSpace, for health behaviour change. We combine the Social Cognitive Theory from health behaviour that underpins the importance of social aspects of healthy living with the Uses and Gratifications Theory that provides motives for participation in OSNs. The justification for this approach is that our OSN needs to be engaging in order for it to be used, so we look to the Uses and Gratification Theory to provide the factors that motivate use of OSNs [17,19]. Similarly, the factors for health behaviour change from the Social Cognitive Theory [4] are also applied to the design with an aim to change health behaviour. This theoretical approach is undertaken to create better design principles that help people to both start and maintain healthy habits. Others have used health behaviour theories to design technologies for motivating increased physical activity, improved nutrition, or both; however, the factors from the Social Cognitive Theory have not been directly used to design and evaluate technology to promote positive health behaviour. Furthermore, the Social Cognitive Theory has never been combined with the Uses and Gratification Theory to ensure engagement in the technology. Finally, OSNs have not been explicitly designed for the purpose of health behaviour change before. This work informs research in both HCI and Persuasive Technologies [12], and guides the design of the multitude of applications that are coming to market for fitness and improved diet.

In our design of an OSN, VivoSpace, we chose to focus on healthy eating and physical activity as both are closely linked to health outcomes such as ideal weight, prevention of illness and management of chronic diseases [7,2,15]. We are not focusing on weight loss specifically, but rather nutritious eating habits and physical activity over sedentary lifestyle. We deployed VivoSpace to three separate social network groups in both Canada and the United States in a 4-week study with 35 participants. 
We use the factors from the theories to create design elements that ensure engagement in VivoSpace and changes in health behaviour. In providing this contribution, the main outcomes of this study are: 1) an understanding of different social dynamics in small social network group through use of an OSN for healthy; and 2) details of design mechanics in an OSN that influence health behaviour and motivation to continue to use the website.

\section{Foundational Theories}

Theoretical models assist us to understand human behaviour. The theories used in our approach to design, prototype and evaluate VivoSpace are the Social Cognitive Theory and the Uses and Gratification Theory. Various HCI researchers have considered the Social Cognitive Theory in designing social technologies to influence health behaviour change (as described in the Related Work Section). We build upon previous works by utilizing the Social Cognitive Theory as a foundation for our design and evaluation. We did not directly use other health behaviour theories in our approach, as we wanted to provide clarity in linking factors for health behaviour change from the theory to the design. Further, as engagement in the technology is necessary for the system to be used, we apply the Uses and Gratifications Theory to derive design strategies for motivating the use of the OSN. In other words, the OSN needs to be used in order for the design elements for health behaviour change from the Social Cognitive Theory to be effective.

\subsection{Social Cognitive Theory}

The Social Cognitive Theory holds that behaviour is determined through expectancies and incentives, and of key importance is self-efficacy to changing health behaviour [3,4]. The Social Cognitive Theory [4] was first drawn from the Social Learning Theory by [3], and it was further developed into five core determinants of health behaviour change:

1. Knowledge is an individual's knowledge of and expectations of outcomes related to the health risks and benefits of different health practices.

2. Perceived Self-Efficacy is an individual's own competence to perform the behaviour needed to influence outcomes and the individual's ability to exercise control over one's health habits. Perceived Self-Efficacy can be influenced vicariously through others, which allows for social modeling and the building of social norms.

3. Goals include proximal and distal goals, and they need to be concrete plans and include strategies to realize them. This factor builds accountability.

4. Perceived Facilitators include social and structural factors, and social approvals and social supports can be facilitators. They incorporate the value of the outcome of health behaviour change, which can be health, appearance, social approval, or economic gain.

5. Perceived Impediments is the opposite of perceived facilitators, and they also include both social and structural factors. 


\subsection{Uses and Gratification Theory}

The Uses and Gratifications Theory originated from communications research and is generally recognized to be a sub-tradition of media effects research [28]. Initially, it provided a theoretical approach in defining the motivations for using traditional mass media such as newspaper, radio and television [35]. It has received renewed interest because of its applicability to telecommunications, computer-mediatedcommunication [34,11] and the Internet [30]. It has also been applied to online communities [11,19], and more recently, uses and gratifications has been studied to understand the motivations for using Facebook® [17].

We consider five key works based that present motivational factors based on the Uses and Gratification Theory on their application to the Internet, online communities, and OSNs $[11,19,30,35,17]$. By reviewing these works, we find that there are eight main motivational factors that influence use of OSNs based on the Uses and Gratification Theory:

1. Entertainment refers to a motivation that stems from enjoyment of playing or interacting with others [30,11,19], and also encompasses Diversion [35] and the need to Pass Time [30].

2. Social Enhancement is a value that one ties to their status within social peers [11,17], and is also linked to Social Utility [35] and Interpersonal Utility [30].

3. Maintaining Interpersonal Connectivity pertains to sustaining contact with one's social networks [11,19], and it also relates to Social Utility [35] and Interpersonal Utility [30], or as Joinson describes as Social Connection [17].

4. Self-Discovery occurs when self-knowledge is obtained through social interaction $[11,19]$, and it includes Personal Identity, which is a reinforcement of ones values, attitudes and beliefs [35].

5. Get Information is an instrumental purpose like receiving information [11,19], and it can also overlap with Information Seeking [30] and Surveillance [35]. It also suggests social sharing, which includes factors such as Content Creation and Curation, Social Network Surfing, and Social Investigation [17].

6. Provide Information is democratized with online communities and OSNs compared to previous media, and refers to a motivational factor that is unique from Get Information [19]. In OSNs, we see Status Updating [17] as a specific means of Providing Information.

7. Convenience provides an understanding of why people would choose to use the Internet as opposed to read the newspaper, or socialize via an OSN service as opposed to meet in person. This factor was only described by [30].

8. Shared Identity occurs as one constructs their identities through the use of an OSN and relates to others through shared interests and values [17].

\section{Related Work}

Although OSNs have not been studied specifically for health behaviour change, technologies with social components designed for health behaviour change have been 
explored by HCI and Persuasive Technology communities. We build on this work by specifically looking at the design of OSNs through the use of theoretical models. Some of the works that have incorporated social aspects in their design have considered the Social Cognitive Theory. We also review studies that investigated social aspects of health behaviour without consideration of the Social Cognitive Theory. Finally, we present some works that did not investigate social aspects for health behavour change as a central component of their study, but their results informed our work. A description of all these studies is presented in Table 1. There are no works that combined the Social Cognitive Theory with the Uses and Gratification Theory to design of an OSN for health behaviour change.

Table 1. List of related works showing the name of the application developed, description of the application, and the number of participants (p) and duration of the evaluation

\begin{tabular}{|c|c|c|}
\hline Application Name & Description & Evaluation \\
\hline $\begin{array}{l}\text { Stepping Up for } \\
\text { Health (SUH) [34] }\end{array}$ & $\begin{array}{l}\text { Internet mediated walking program that measured the } \\
\text { impact of adding an online community on the walking } \\
\text { habits of individuals. }\end{array}$ & $324 \mathrm{p}, 16 \mathrm{wks}$ \\
\hline VERA [5] & $\begin{array}{l}\text { Users take pictures at moments when they make health } \\
\text { decisions and provide annotation about the picture's rela- } \\
\text { tion to health. }\end{array}$ & $\begin{array}{l}45 \mathrm{p}, 2 \text { wks; } 44 \mathrm{p} \text {, } \\
4 \text { wks }\end{array}$ \\
\hline Shakra [1] & $\begin{array}{l}\text { Mobile phone application infers whether the user is still, } \\
\text { walking or traveling in a car, and provides and shares the } \\
\text { amount of time that the user was active with some competi- } \\
\text { tion features. }\end{array}$ & $9 \mathrm{p}, 1 \mathrm{wk}$ \\
\hline Fish'n'Steps [21] & $\begin{array}{l}\text { Links users' step counts to the growth and happiness of a } \\
\text { virtual fish. }\end{array}$ & $19 \mathrm{p}, 14$ wks \\
\hline Houston [9] & $\begin{array}{l}\text { Pedometer and mobile phone application that allows users } \\
\text { to set goals. It includes a sharing version and a personal } \\
\text { version. }\end{array}$ & $13 \mathrm{p}, 3$ wks \\
\hline $\begin{array}{l}\text { Lifestyle Coaching } \\
\text { Application [14] }\end{array}$ & $\begin{array}{l}\text { Smart phone and website version where users diary their } \\
\text { food and physical activity, set goals and provide a points } \\
\text { system for a game experience. }\end{array}$ & $40 \mathrm{p}, 4$ wks \\
\hline EatWell [16] & $\begin{array}{l}\text { Social mobile phone application designed to assist African } \\
\text { American communities make better food choices, where } \\
\text { users share audio recordings of experiences related to food. }\end{array}$ & $12 \mathrm{p}, 4$ wks \\
\hline Chick-Clique [37] & $\begin{array}{l}\text { Mobile application provides sharing of step counts, visibil- } \\
\text { ity of group averages, and text messaging capability. }\end{array}$ & 7 girls, 4 days \\
\hline MAHI [27] & $\begin{array}{l}\text { Mobile application to communicate with one's diabetic } \\
\text { educator. }\end{array}$ & 49 p, 6 mo. \\
\hline $\begin{array}{l}\text { UbiFit Garden } \\
{[10]}\end{array}$ & $\begin{array}{l}\text { Wallpaper of the users cell phone shows a garden. Flowers } \\
\text { appear with more physical activity, and it shows butterflies } \\
\text { as goals are met. }\end{array}$ & $\begin{array}{l}12 \mathrm{p}, 3 \text { wks; } 28 \mathrm{p}, \\
3 \mathrm{mo}\end{array}$ \\
\hline IMPACT [20] & $\begin{array}{l}\text { A step-count personal informatics system that is evaluated } \\
\text { to understand the influence of context on step count. }\end{array}$ & $49 \mathrm{p}, 8$ wks \\
\hline Fit4Life [33] & $\begin{array}{l}\text { A mock design of a health system that collects dietary and } \\
\text { activity level, shares on OSN sites, and provides advice. }\end{array}$ & N/A \\
\hline
\end{tabular}

Since the Social Cognitive Theory postulates that health is a social matter and not just an individual one, we look at three works that have considered this theory in the design of their technologies. First, the SUH [34] study considered social support and 
social modeling from the Social Cognitive Theory to explain how the online community experimental group can promote increased step count and lower attrition. The study found that individuals were more engaged and participant attrition was lower with those that used the online community version. However, the Social Cognitive Theory was not central in the design and evaluation of SUH. Second, the VERA system [5] showed that the social aspects allowed participants to mimic others, and that the system built group identity and allowed for greater accountability. Although the authors did mention that the design of VERA was consistent with social modeling and accountability aspects from the Social Cognitive Theory, the use of the theory was not central in the design and evaluation. Third, the Shakra [1] system loosely based the social aspects of their design on the Social Cognitive Theory to show that community was important to health behaviour. Shakra did not show any increase in activity, but the participants enjoyed the sharing and competition aspects. We expand the use of the Social Cognitive Theory by anchoring the design and evaluation of our OSN on factors from the Social Cognitive Theory as well as the Uses and Gratification Theory.

Other HCI researchers have done significant work in considering social aspects when designing health technologies without the use of the Social Cognitive Theory. The results from these studies are mixed; however, the social aspects did lead to building community empowerment and social supports. The Fish'n'Steps [21] used the Transtheoretical Model to evaluate the stage or level of health behaviour change of the study participants, but did not use the theory in the design of the system. The Houston [9] system showed those that used the sharing version met their goals more often than those that used the personal version. The Lifestyle Coaching Application [14] revealed no significant difference between mobile and web versions, or individual and team player groups. The qualitative analysis for EatWell [16] revealed that the use of the system led to a sense of empowerment for the community, as users were from the same geographic location. Chick-Clique [37] showed an increased step count for one group, but not the other, due to confounding reasons. Finally, the MAHI system allowed for social support for newly diagnosed diabetics [27], and a means to construct one's identity for those that have been living with diabetes for more than one year [26]. The variable results can be better understood with the use of theoretical models in the design and evaluation of these systems, which can provide insight into how these systems were successful in achieving health behaviour change and how they can be improved.

The HCI community produced other works related to health behaviour change that inform our study, where social aspects did play a role in their work although it was not a central part of their study. First, the UbiFit Garden [10] took a theoretical approach to develop design strategies for health behaviour change; however, different theoretical models were used and the UbiFit Garden was not an OSN, so our work extends this approach to the design of an OSN to change health behaviour. Secondly, the IMPACT system was created to better understand the influence of context on personal health informatics [20], where social influence is a critical part of context. Finally, another work that deserves mention is a mock parody design called Fit4Life, 
which shows the importance of mindfulness in understanding our behaviour, and the privacy concerns of posting our health behaviours on large OSN services such as Facebook® [33].

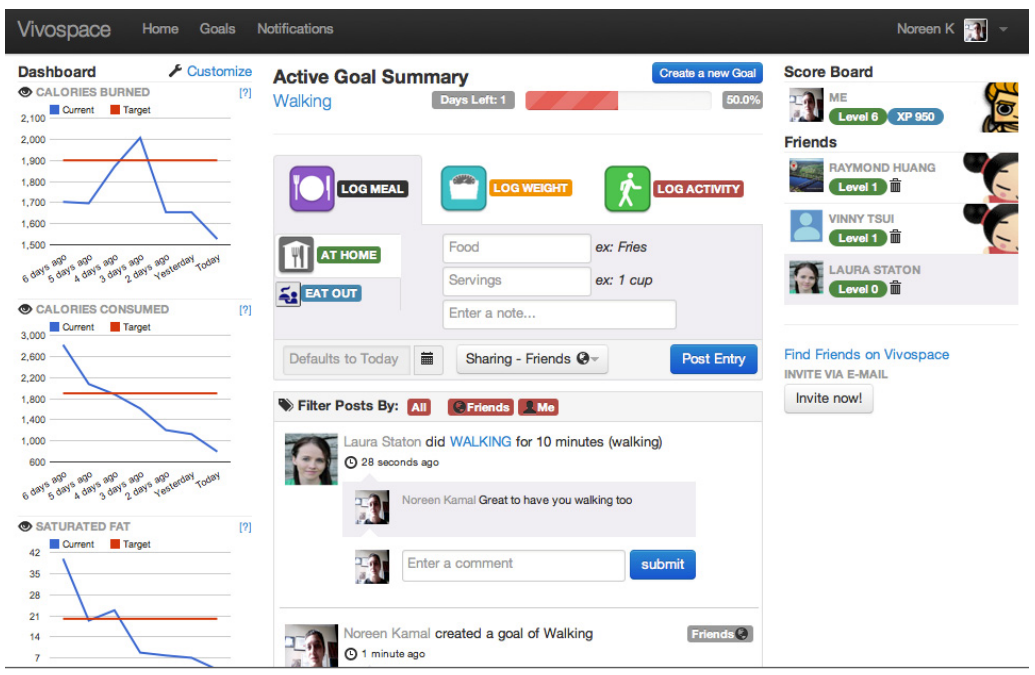

Fig. 1. Main home page of VivoSpace showing the Dashboard on the left; the goals summary, $\log$ entry and newsfeed in the middle; and friends with game progress on the right, each level has a character associated with it

\section{$4 \quad$ Designing and Prototyping VivoSpace}

By blending the five key factors that influence health behaviour change from the Social Cognitive Theory and the eight factors that motivate the use of OSNs from the Uses and Gratifications Theory, we designed VivoSpace. The VivoSpace system provides features that promote eating healthy foods and engaging in physical activity because both are important to good health behaviour. The design of VivoSpace was developed through a User-Centered Design process, initially with paper prototypes that were evaluated using one-on-one interviews with 11 people, and then with a medium-fidelity prototype that was evaluated in a laboratory with 36 people [18]. These studies revealed that the VivoSpace design allowed for greater understanding of one's health behaviour, but social gaming features were needed to build motivation to use the system. Finally, this high-fidelity prototype was tested with seven individuals using a cognitive walk-through prior to the field study described in this paper. The high fidelity prototype was developed using PHP and MySQL within the CodeIgniter application framework. Twitter's® Bootstrap was used for the user interface elements and Doctrine PHP libraries were used for the database abstraction layer. Furthermore, VivoSpace incorporates Wolfram Alpha' ${ }^{\circledR}$ Application Programming Interface (API) to obtain nutritional information for meals and caloric expenditure for physical 
activities logged. When the API cannot return the nutritional information, a site administrator enters the correct information based on web searches, which we anticipate will eventually be crowd-sourced.

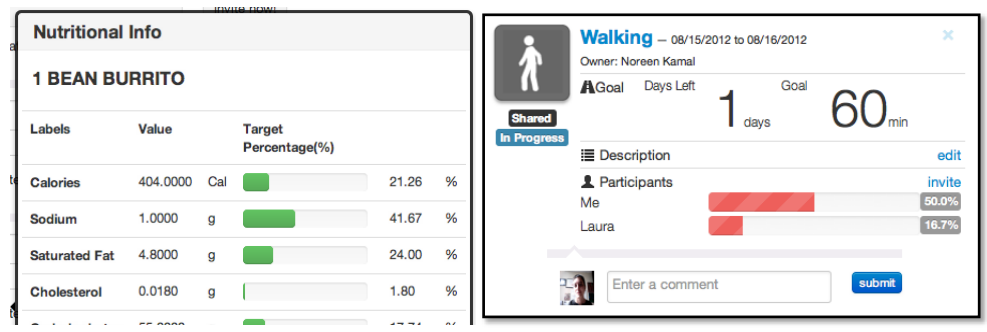

Fig. 2. Left: the nutritional content of a meal is displayed when the logged meal is clicked. Right: goal details show the user's and participating friend's progress towards the goal target.

VivoSpace has three main components: logging, goals, and a personal dashboard. The main home page of VivoSpace is shown in Fig. 1. Users have the ability to log their meals, physical activity and weight. After users log their meals, the nutritional content of the meals is available when they click on the name of the food (Fig. 2. left). Similarly, when they log a physical activity, the caloric expenditure is available. Users have the ability to make a log private or to share it with their social network. The newsfeed shows the log entries for themselves and their friends (we will use the word "friend" to refer to social connections on VivoSpace). The shared log entries allow for commenting between the individuals in the user's social network. The historical trends for calories consumed, calories burned, and each nutrient is charted on the dashboard, which is always visible on the left side of the home page. User's can customize their targets for each of the nutrients or use the defaults, which are based on US and Canadian national standards. Users also have the ability to create concrete proximal goals from a library of goals such as walk for 60 minutes over 2 days, or eat $35 \mathrm{~g}$ of fiber over 3 days. They can invite friends to participate in their goals with them. The goal progress is shown on the home page, and details are shown when the user clicks on the goal (Fig. 2. right). VivoSpace also provides the following gamification features: users earn small experience points (XP) by using VivoSpace and major experience points for successfully completing goals. Users progress through 10 levels with each level requiring more points to advance to the next level. Furthermore, each level reveals a new character. These design elements are developed based on the factors from the Social Cognitive Theory and the Uses and Gratification Theory, which are mapped on Table 2.

\section{The Study}

The VivoSpace OSN provides design mechanics that should promote motivation to use the system, as well as promote health behaviour change by applying factors from the Uses and Gratifications Theory and the Social Cognitive Theory (respectively). 
We evaluated VivoSpace in a field study with three separate social networks in both Canada and the United States. This study's contribution is the application of theories to design and evaluate an OSN for health behaviour change. Since we look at three distinct social networks, we provide a discussion on how different social dynamics within a social network contribute to healthy behaviour through the use of VivoSpace. We provide details for which design elements contribute to positive health behaviour change within VivoSpace, and how the design can be modified to further contribute to health behaviour change.

Table 2. Mapping of the five factors from the Social Cognitive Theory and eight factors from the Uses and Gratification Theory to the design elements provided on VivoSpace

\begin{tabular}{|c|c|c|}
\hline & Factor & VivoSpace Design Mechanic \\
\hline \multirow{5}{*}{ 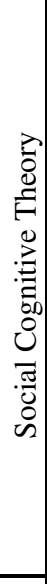 } & Knowledge & $\begin{array}{l}\text { Knowledge is obtained through the nutritional value for logged } \\
\text { meals and caloric expenditure for logged physical activity. Infor- } \\
\text { mation about the definition of each nutrient is available through a } \\
\text { help link beside the name of the nutrient. }\end{array}$ \\
\hline & Perceived Self-Efficacy & $\begin{array}{l}\text { Seeing historical log entries and charts of nutrients consumed on } \\
\text { the dashboard shows one's capability to eat healthy and be physi- } \\
\text { cally active. Also seeing the log entries of others builds self- } \\
\text { efficacy vicariously through others by social modeling. }\end{array}$ \\
\hline & Goals & $\begin{array}{l}\text { Proximal goals can be created and they are always visible at the } \\
\text { top of the homepage. Distal goals are achieved through the charts } \\
\text { (on dashboard) displaying historical trends and targets. }\end{array}$ \\
\hline & Perceived Facilitators & $\begin{array}{l}\text { Visibility of others' activities allows users to mimic behaviour, } \\
\text { and the commenting on shared entries provides dialogue for en- } \\
\text { couragement. The gaming features provide motivation. }\end{array}$ \\
\hline & Perceived Impediments & $\begin{array}{l}\text { The commenting feature on shared log entries can provide dia- } \\
\text { logue with one's friends to overcome barriers. }\end{array}$ \\
\hline \multirow{8}{*}{ 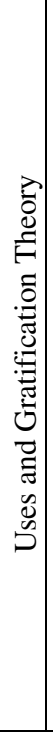 } & Entertainment & $\begin{array}{l}\text { The gaming features include the accumulation of experience } \\
\text { points and advancement through } 10 \text { levels. }\end{array}$ \\
\hline & Social Enhancement & $\begin{array}{l}\text { Social enhancement is provided by: 1) visibility into the level } \\
\text { obtained by one's friends; 2) visibility into the shared meals of } \\
\text { one's friends; and 3) participating with a friend on a goal and } \\
\text { seeing their progress towards the target. }\end{array}$ \\
\hline & $\begin{array}{l}\text { Maintaining Interper- } \\
\text { sonal Connectivity }\end{array}$ & $\begin{array}{l}\text { Social connection is provided through the ability to comment on } \\
\text { friends' log entries and participate with friends on goals. }\end{array}$ \\
\hline & Self-Discovery & $\begin{array}{l}\text { Ability to see the nutritional value of foods eaten and caloric } \\
\text { expenditure for physical activity and the historical trends on the } \\
\text { dashboard allow users to discover their health behaviour. }\end{array}$ \\
\hline & Get Information & $\begin{array}{l}\text { Nutritional information is obtained for each log entry, and histori- } \\
\text { cal information is available on the dashboard. }\end{array}$ \\
\hline & Provide Information & $\begin{array}{l}\text { Information is provided through logging of meals, physical activi- } \\
\text { ty, and weight, and through commenting on friend's entries. }\end{array}$ \\
\hline & Convenience & $\begin{array}{l}\text { Obtaining the nutritional value of foods and caloric expenditure of } \\
\text { physical activity, and having a historical storage of one's nutri- } \\
\text { tional information provided convenience of access to information. }\end{array}$ \\
\hline & Shared Identities & $\begin{array}{l}\text { Through the sharing of one's meals and physical activity, and } \\
\text { allowing friends to comment on these entries. }\end{array}$ \\
\hline
\end{tabular}




\subsection{Methods}

Recruitment and Participant Overview. We recruited a total of 35 participants from three different settings including clinical and non-clinical settings. For the clinical groups, we considered patients that are associated with the same clinic, share the same geographic location, and are generally from the same socioeconomic status, as was found to be important by Grimes et al. [16].

The first group of participants from a clinical setting was recruited from a primary care clinic in suburban Chicago, which has a focus on wellness and weight loss. A total of 22 participants were recruited by sending an email through the clinic's patient portal. Half of the participants were randomly assigned to the control group and the other half to the experimental arm. The participants in the experimental group used VivoSpace during the 4-week study period, while participants in the control group did not use VivoSpace. The reason for having a control group was to control for newly acquired health behaviours from association with the clinic.

The second group of participants from a clinical setting was recruited from an integrative medical center in Vancouver, Canada. This clinic provides a focus on prevention and partnership between physician and patient. Participants were recruited from their medical-group-visit patients, where patients meet with a physician as a group, so they already take advantage of social aspects to good health. A total of 3 participants were recruited from this clinic. The small number reflects the limited number of patients that take part in the medical group visits, and it means that we could not have a control group for this clinic. The participants were recruited through direct email contact from the clinic.

The non-clinical group of participants was a close-knit group of colleagues at a small software gaming company in Vancouver Canada, where all the employees have good knowledge of each other. A total of 10 participants were recruited by directly asking the employees of the company. The company has a total of 35 employees. There was no control group for the non-clinical group, as they were not associated with a wellness or integrative medical clinic, and we used the results from the prequestionnaire (see Measures section below) to evaluation their health without VivoSpace.

Table 3. An overview of the participants recruited for the field study showing gender distribution, age, obesity, and their rank of their healthiness (1-6 Likert Scale, 1=very unhealthy)

\begin{tabular}{|c|c|c|c|c|c|c|c|}
\hline Group & $\begin{array}{l}\text { Male } \\
\text { (n) }\end{array}$ & $\begin{array}{l}\text { Female } \\
\text { (n) }\end{array}$ & $\begin{array}{l}\text { Mean Age } \\
\text { (range) }\end{array}$ & $\begin{array}{l}\text { SD } \\
\text { Age }\end{array}$ & $\begin{array}{l}\text { Over- } \\
\text { weight } \\
\text { (n) }\end{array}$ & $\begin{array}{l}\text { Obese } \\
\text { (n) }\end{array}$ & $\begin{array}{l}\text { Mean Health } \\
\text { Rank }\end{array}$ \\
\hline Chicago Clinic (exp) & 2 & 8 & $48.15(24-76)$ & 17.3 & 2 & 5 & $2.9(\mathrm{SD}=1.3)$ \\
\hline Chicago Clinic (cntl) & 0 & 9 & $58.22(29-68)$ & 11.8 & 4 & 3 & $3.9(\mathrm{SD}=1.0)$ \\
\hline Vancouver Clinic & 0 & 3 & $48.0(44-57)$ & N/A* & 1 & 0 & $3.0(\mathrm{SD} N / \mathrm{A})$ \\
\hline Non-Clinical Group & 4 & 6 & $32.6(20-46)$ & 7.4 & 3 & 0 & $4.6(\mathrm{SD}=0.9)$ \\
\hline
\end{tabular}

*Number of participants is too small $(n=3)$ for standard deviation to be meaningful. 
A total of 35 participants were recruited from three groups: Chicago clinic (11 in experimental group and 11 in control group), Vancouver clinic (3), and the nonclinical group from the Vancouver gaming company (10). Out of the 22 participants recruited from the Chicago clinic, 3 dropped out prior to the end of the study. One was in the experimental group, and the other two were in the control group. Table 3 shows an overview of the remaining participants from all three groups. Overall, there is a bias towards women. Furthermore, the participants from the non-clinical group were younger than those from the clinics, and this group ranked their health better than those from the clinics (health was ranked on a 6-point Likert scale, where 1=very unhealthy and 6=very healthy).

Participants from each group were asked to friend each other, but there was no friending across the social networks, so that we could evaluate the social dynamic within each group. All participants received a $\$ 50$ honorarium.

Measures. All participants completed a pre-questionnaire prior to the start of the study and post-questionnaire after the 4-week study period. The questionnaires both had the following: 1) current health behaviour; 2) knowledge test of nutrients; and 3) 5-point Likert questions that linked back to the factors from the Social Cognitive Theory. The post-questionnaire for those participants that used VivoSpace also included the following: 1) 5-point Likert questions that linked back to the factors from the Uses and Gratification Theory; and 2) open-ended qualitative responses about their thought on VivoSpace and how it contributed to health behaviour change. Change in health behaviour was analyzed through comparison between the pre- and post-questionnaires.

The first set of questions that inquired about health behaviour included: questions about height and weight to obtain a body-mass-index in order to assess if the participant was overweight or obese; the number of salads, vegetables, fruits, French fries and potato chips that they ate in the past week (no other foods were enquired about); and how often they walked, performed cardio exercise, and other physical activity in the past week. The current stage in health behaviour change from the Transtheoretical model was also inquired, as was done by $[9,21,23]$. The Transtheoretical Model defines the stages of change as pre-contemplation, contemplation, preparation, action, and maintenance [32].

The second set of questions was a 10-question multiple-choice test on the meaning of nutrients to assess knowledge. They included question such as, "What foods have the highest fiber content?" The answers included: a) whole wheat breads, beans, and vegetables; b) any breads and cereal grains; c) whole wheat bread and meats; and d) all of the above.

The third set of questions was 5-point Likert style questions that asked for the level of concurrence on statements that mapped to the factors from the Social Cognitive Theory. For example, the statement for perceived self-efficacy for eating nutritious foods stated, "I am capable of eating highly nutritious foods and resisting unhealthy foods." The 5-point Likert questions ranged from "strongly disagree" (1) to "strongly agree" (5).

The post-questionnaires for those participants in the experimental group also included 5-point Likert questions for the eight factors from the Uses and Gratification 
Theory. The post-questionnaire also inquired about which design features of VivoSpace contributed to the factors from the Social Cognitive Theory. For example, after the afore mentioned Likert question on perceived self-efficacy, another 5-point Likert statements inquires concurrence with, "I was able to learn about my capabilities by logging my meals on VivoSpace"

The open-ended qualitative responses included general thoughts on VivoSpace and how it can be improved to motivate use and health behaviour change, and specific responses for how it can provide factors from both theories more effectively.

\section{$6 \quad$ Results}

The results cover the following: 1) whether the incorporation of the Uses and Gratification Theory into the design encouraged use of VivoSpace; 2) whether the incorporation of the Social Cognitive Theory led to an increase in the self-report on the five factors from this theory; 3) and if there was any observed change in health behaviour at the end of the 4 weeks. Analysis includes statistical comparison of pre- and postquestions as well as qualitative analysis of open-ended free form questions.

\subsection{Overview of System Use}

The use of VivoSpace over the 4 weeks varied substantially. All 23 participants that were using VivoSpace created an account and friended others from their network group. The participants from the non-clinical group (Vancouver gaming company) used it more than those from the Chicago clinic, which can likely be attributed to this group's ease with technology. One participant from the Vancouver clinic used the system the most. Table 4 shows an overview for usage of VivoSpace for all three groups. The nonclinical group was less inclined to share their entries than those from the clinical groups. The comments included: encouragement about the post, "good job!" and "Woot!"; additional information about the food or activity entered, "Santa Cruz organic added to Perrier"; or their feeling about the activity, "I love Thai food, yum".

Table 4. Overview for usage of VivoSpace for all three groups, includes the mean and range of $\log$ entries made, disclosure of log entries, and total comments made for each group

\begin{tabular}{lllll}
\hline Group & $\begin{array}{l}\text { Mean \# of log } \\
\text { entries }\end{array}$ & $\begin{array}{l}\text { Min-max \# of } \\
\text { log entries }\end{array}$ & $\begin{array}{l}\text { \% private log } \\
\text { entries }\end{array}$ & $\begin{array}{l}\text { Total \# of } \\
\text { comments }\end{array}$ \\
\hline Chicago Clinic & $18.3(\mathrm{SD}=27.4)$ & $0-83$ & $2.2 \%$ & 20 \\
Vancouver Clinic & $93(\mathrm{SD}=161.1)$ & $0-279$ & $1.1 \%$ & 19 \\
Non-Clinical Group & $54.6(\mathrm{SD}=63.3)$ & $2-184$ & $59.2 \%$ & 24 \\
\hline
\end{tabular}

The questionnaire also inquired about each participant's perception of use based on the eight factors from the Uses and Gratifications Theory. The results of the 5-point Likert responses for all three groups are shown in Table 5. The strongest factors for motivating use were to Provide Information and Self-Discovery for all groups; 
however, interestingly Shared Identity was strong only for the loose social connections of the clinical groups. Although the Likert response for to Get Information was a bit lower with mean of 2.67 for the non-clinical group, the qualitative responses showed that they did use it to receive information; for example, "I liked watching my vitamin consumption over time" (P9). The qualitative responses for the Chicago clinic revealed sentiment for the Shared Identity motivational factor; such as, "I liked being supportive to like minded people achieving goals"(P32). The Vancouver clinic had one active user, who was the heaviest user of VivoSpace. She continued to use it on a daily basis despite the fact that the she did not have the full social experience of $V i$ voSpace. This user had some mistrust in the nutritional and energy expenditure information that was provided by VivoSpace, "I'm not sure how accurate the nutritional and calorie burning info was, and I think that more detailed information would need to be made available for it to be useful" (P31). With respect to Self-Discovery, she said, "It was interesting to be accountable; it made me think more about it" (P31).

Table 5. Mean values for results of 5-point Likert Scale responses for the Uses and Gratification Theroy for all 3 groups

\begin{tabular}{lllllllll}
\hline Group & $\begin{array}{l}\text { Enter- } \\
\text { tainment }\end{array}$ & $\begin{array}{l}\text { Social } \\
\text { Enhance- } \\
\text { ment }\end{array}$ & $\begin{array}{l}\text { Maintain } \\
\text { Connec- } \\
\text { tivity }\end{array}$ & $\begin{array}{l}\text { Self } \\
\text { Discov- } \\
\text { ery }\end{array}$ & $\begin{array}{l}\text { Get } \\
\text { Infor- } \\
\text { mation }\end{array}$ & $\begin{array}{l}\text { Provide } \\
\text { Infor- } \\
\text { mation }\end{array}$ & $\begin{array}{l}\text { Conven- Shared } \\
\text { ience }\end{array}$ & Identity \\
\hline Chicago Clinic & 2.14 & 1.71 & 2.0 & 2.42 & 1.57 & 2.85 & 2.17 & 2.85 \\
Vancouver Clinic & 3.5 & 3.0 & 2.0 & 3.5 & 2.5 & 3.5 & 2.5 & 3.0 \\
Non-Clinical Group & 2.44 & 2.78 & 2.67 & 3.11 & 2.67 & 3.0 & 2.33 & 2.22 \\
Overall Mean & $\mathbf{2 . 4 4}$ & $\mathbf{2 . 3 9}$ & $\mathbf{2 . 3 3}$ & $\mathbf{2 . 8 9}$ & $\mathbf{2 . 2 2}$ & $\mathbf{3 . 0 0}$ & $\mathbf{2 . 2 9}$ & $\mathbf{2 . 5 6}$ \\
\hline
\end{tabular}

\subsection{Change in Key Factors from Social Cognitive Theory}

The responses from pre- and post-questionnaires were compared using paired t-tests for both the non-clinical and clinical groups. Paired t-tests were done for the Chicago clinical group and combined clinical experimental group (both Vancouver clinic and Chicago clinic). Due to the small number of participants from this clinic, independent t-test with only the Vancouver clinic could not be done. The results from the Chicago clinical experimental group and combined clinical experimental group were compared with the Chicago control group.

Knowledge. Knowledge was measured in two ways: 1) through a 10-question multiple choice test; and 2) through direct inquiry via a 5-point Likert scale question. There was no statistically significant difference between any of the groups: nonclinical group; all clinical groups; Chicago clinic experimental group; and Chicago clinical control group. The participants did not gain any knowledge of nutritional content of food consumed and physical activity. Users felt that there should have been other ways to obtain health information, as in the following qualitative response, "It would be nice if I could ask VivoSpace the nutritional information for a Big Mac or something that is for food that is not eaten" (P7). Others wished that VivoSpace provided more prescriptive advice on how to change behaviour, "How can I have more vitamin C in my diet? I would like a recommendation on what I should eat" (P6). 
Perceived Self-Efficacy. A central concept to the Social Cognitive Theory is Perceived Self-Efficacy. The paired t-tests for all groups showed a statistically significant increase between the pre- and post-questionnaires' 5-point Likert scale inquiry into one's Self-Efficacy (Fig. 3). The greatest increase was observed for the Chicago clinical experimental group and the smallest increase was observed for the non-clinical group. However, these results need to be taken with caution, as the control group from the Chicago clinic also showed an increase in Perceived Self-Efficacy, which perhaps means that there were other factors contributing to the increase in self-efficacy such as association with the Chicago clinic.

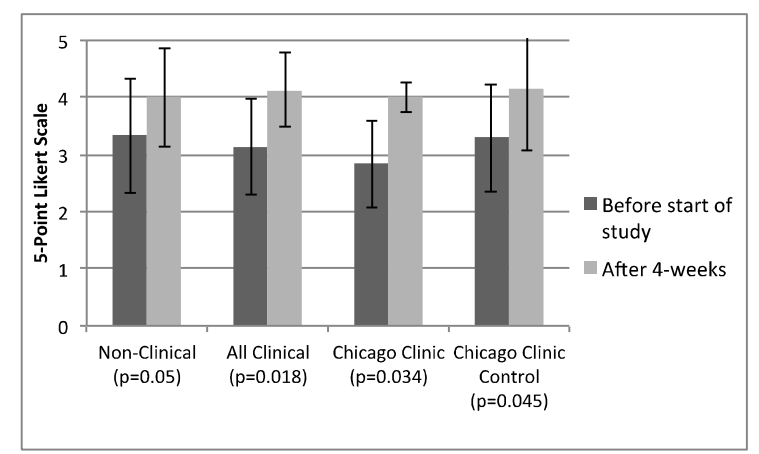

Fig. 3. The pre and post results of self-reported perceived self-efficacy for eating nutritious foods using a 5-point Likert scale. Mean values are represented with the error bars showing SD.

For those using VivoSpace, we also inquired about the aspects of VivoSpace that contributed to their self-efficacy. Generally, the participants felt that logging their meals and physical activity can lead to increasing their understanding of their capability.

Goals. The statistical analysis revealed no significant difference. The qualitative responses showed that users wanted to be able to customize their goals, "most of the goals currently in the system were not appropriate for me so there was nothing for me to do with other members" (P7). Making the goals more social and more central to the system also can contribute to more creation and completion of health goals, as one participant says, "putting [the goals] out there for people to see" (P32).

Perceived Impediments and Facilitators. No statistically significant difference was observed for either decreasing perceived impediments or increasing perceived facilitators. Most users of VivoSpace felt that the system's ability to provide their nutritional information does assist them to reduce impediments or increase facilitators. However, as one participant points out, time constraints are the biggest impediment to healthy behaviour, and logging one's information on VivoSpace takes time (P28). This perhaps shows the need for the system to have reminders, as suggested by P1. There were some features that some participants found to be facilitators: "I like having the charts to show my progress; especially seeing my weight line go down" (P28); and "nutritional information regarding foods I was eating helped push me to keep cooking those foods or avoiding other foods" (P9). 


\subsection{Changes in Health Behaviour}

There was health behaviour change observed between the pre- and post-questionnaires for the Chicago clinic experimental group and a strong trend toward health behaviour change for the other two experimental groups. The Chicago clinic experimental group increased the number of salads they ate in a week with a mean difference of $1.0(t=2.65$, $\mathrm{p}<0.05$ ). For the non-clinical group, the number of servings of potato chips (and similar foods) consumed in a week went down with a mean difference of $-0.56 \quad(t=1.89$, $\mathrm{p}=0.095$ ). For the clinical group (combination of both clinics), we saw a strong trend toward a positive move in the stages of change from the Transtheoretical Model [32] with a Wilcoxon Signed Ranks test $(\mathrm{Z}=1.84, \mathrm{p}=0.066)$. By comparison, there was no health behaviour change observed in the Chicago clinic control group.

\section{Discussion}

An OSN can change health behaviour if it is designed with features that influence factors from theoretical models. The results for health behaviour change do not show large changes, but the small steps towards healthier living are encouraging because positive health behaviour change did occur in some way for each of the experimental groups, and did not occur for the control group. The maintenance of these new behaviours is not known at this time, but would be important to investigate further. By evaluating VivoSpace with the use of the Social Cognitive Theory and Uses and Gratification Theory, we can better understand which design elements contributed to health behaviour change; furthermore, the results reveal the factors from the theories that were not provided in the design of VivoSpace, which provide possibilities for design improvement.

Logging meals and physical activities to reveal the nutritional value of meals and caloric expenditure of activities combined with charts showing trends of calories and nutrients consumed build perceived self-efficacy. The greatest increase in self-efficacy was observed in the Chicago clinical experimental group, which suggests that the process of logging meals and physical activity does build self-awareness. By logging health information, users become more accountable and aware of their capabilities.

The design can be improved by also providing nutritional information for foods not eaten) and having tailored messages for how to improve health behaviour to build knowledge. The qualitative results show that the design can be modified to promote an increase in knowledge of nutritional value of food and energy expenditure of physical activities. The participants suggested that VivoSpace could assist them to make decisions about food, so it should have the ability to obtain nutritional information for foods that were not eaten. Further, VivoSpace can be more prescriptive and provide tailored messages for how the user can make healthier choices.

Providing reminders for goals and allowing for customizable goals will increase user engagement. The goals feature on VivoSpace should provide reminders to the users after they are set, and goals should be more central in the design. A key change to the goals feature would be to allow users to create customized goals, as the rigidity of the goals provided on VivoSpace led to fewer people creating goals. These changes 
will increase Social Enhancement and make the system more Entertaining; both of which are factors for motivating use from the Uses and Gratification Theory.

Email notifications should be provided when comments are made to one's log entries, and a link should be provided to the log entry and the comment. VivoSpace should provide notifications when comments are made to their posts, or when one responds to one's existing comment. This will increase dialogue between participants, which will build social supports to allow for an increase in the motivation to Maintain Connectivity from the Uses and Gratification Theory and Perceived Facilitators from the Social Cognitive Theory.

Design should include a mobile version and other conveniences such as automatic sensing to ease the time required to use it. The time that was required to enter the data was a contributing factor for some participants to ask for easier means of entering their data. A mobile version and linking to devices such as fitbit ${ }^{\circ}$ to automatically sense steps taken can ease the burden of data entry.

The differences observed between the clinical and non-clinical groups show the potential to use an OSN such as VivoSapce with clinical groups. Overall, both clinical groups disclosed their log entries more than the non-clinical group, and the group from the Chicago clinic saw observable changes in health behaviour. Furthermore, both clinical experimental groups saw the greatest increase in self-reported selfefficacy. The Chicago clinic experimental group showed greater social motivation to use VivoSpace compared with the non-clinical group.

\section{Conclusions}

An OSN called VivoSpace was designed and prototyped based on factors derived from the Uses and Gratifications Theory for use of the OSN, and the Social Cognitive Theory for health behaviour change. Through a 4-week field trial with three social network groups, we used these theories combined with usage data and health behaviour data to evaluate VivoSpace. We were able to determine the design elements through the application of these theories that will lead to use of the system and changes in health behaviour. The study also revealed opportunities to improve the design, so more significant health behaviour change can be observed. We found that a close-knit non-clinical social network group interacts with the system differently than a group of strangers from the same clinic. An OSN such as VivoSpace can be applied to clinical groups, who are associated with the same primary care clinic to improve health behaviour. OSNs such as VivoSpace can provide a health intervention to populations with the greatest need to change health behaviour leading to a healthier population. The use of theoretical models provides an effective means to design and evaluate technologies for health behaviour change.

Acknowledgements. We are thankful for funding from the Canadian Networked Centres of Excellence on Graphics, Animation and New Media (GRAND NCE) and the Institute for Computing, Information and Cognitive Systems (ICICS) at UBC. We thank Raymond Huang and Vincent Tsui for programming VivoSpace. We would also like to thank Michelle Mica Aragon for assisting in contacting participants from the Chicago clinic, and Dr. Lawrence Cheng at Connect Health, Michael Fergusson at Ayogo Games, and Wolfram Alpha ${ }^{\circledR}$ for their support in the study. 


\section{References}

1. Anderson, I., Maitland, J., Sherwood, S., Barkhuus, L., Chalmers, M., Hall, M., Brown, B., Muller, H.: Shakra: Tracking and Sharing Daily Activity Levels with Unaugmented Mobile Phones. Mobile Netw. Appl. 12, 185-199 (2007)

2. Anderson, J.J., Polombo, R.D., Earl, R.: Position of the American Dietetic Association: The Role of Nutrition in Health Promotion and Disease Prevention Programs. J. Am. Diet. Assoc. 98, 205-208 (1998)

3. Bandura, A.: Social Learning Theory. Prentice Hall, Englewood Cliff (1977)

4. Bandura, A.: Health Promotion by Social Cognitive Means. Health Educ. Behav. 31, 143164 (2004)

5. Baumer, E.P., Katz, S.J., Freeman, J.E., Adams, P., Gonzales, A.L., Pollak, J., Retelney, D., Neiderdeppe, J., Olson, C.M., Gay, G.K.: Prescriptive Persuasion and Open-Ended Social Awareness: Expanding the Design Space of Mobile Health. In: Proc. CSCW 2012, pp. 475-484. ACM Press (2012)

6. Berkman, L.F.: The Role of Social Relations in Health Promotion. Psychosomatic Medicine 57, 245-256 (1995)

7. Blair, S.N., Morris, J.N.: Health Hearts and the Universal Benefit of Being Physically Active: Physical Activity and Health. Ann. Epidemiol. 9, 253-256 (2009)

8. Cohen, S.: Social Relationships and Health. Am. Psychol., 676-684 (2004)

9. Consolvo, S., Everitt, K., Smith, I., Landay, J.A.: Design Requirements for Technologies that Encourage Physical Activity. In: Proc. CHI 2006, pp. 457-466. ACM Press (2006)

10. Consolvo, S., McDonald, D.W., Landay, J.A.: Theory-Driven Design Strategies for Technologies that Support Behavior Change in Everyday Life. In: Proc. CHI 2009, pp. 405414. ACM Press (2009)

11. Dholakia, U.M., Bagozzi, R.P., Pearo, L.K.: A Social Influence Model of Consumer Participation in Network- and Small-Group-Based Virtual Communities. Int. J. Res. Mark. 21, 241-263 (2004)

12. Fogg, B.J.: Persuasive Technology: Using Computers to Change What We Think and Do. Morgan Kaufman (2003)

13. Frost, J.H., Massagli, M.P.: Social Uses of Personal Health Information Within PatientsLikeMe, and Online Patient Communities: What Can Happen When Patients Have Access to One Another's Data. JMIR 10, e15 (2008)

14. Gasser, R., Brodbeck, D., Degen, M., Luthiger, J., Wyss, R., Reichlin, S.: Persuasiveness of a Mobile Lifestyle Coaching Application Using Social Facilitation. In: IJsselsteijn, W.A., de Kort, Y.A.W., Midden, C., Eggen, B., van den Hoven, E. (eds.) PERSUASIVE 2006. LNCS, vol. 3962, pp. 27-38. Springer, Heidelberg (2006)

15. Goldstein, L.B., Adams, R., Becker, K., Furberg, C.D., Gorelick, P.B., del Zoppa, G.J.: Primary Prevention of Ischemic Stroke: A Statement for Healthcare Professionals from the Stroke Council of the American Heart Association. Circulation 103, 163-182 (2001)

16. Grimes, A., Bednar, M., Bolter, J.D., Grinter, R.E.: Eatwell: Sharing Nutrition-Related Memories in a Low-Income Community. In: Proc. CSCW 2008, pp. 87-96. ACM Press (2008)

17. Joinson, A.N.: Looking at, Looking Up or Keeping Up with People?: Motives and Use of Facebook. In: Proc. CHI 2008, pp. 1027-1036. ACM Press (2008)

18. Kamal, N., Fels, S.: Determining the Determinants of Health Behaviour Change through an Online Social Network. In: Bang, M., Ragnemalm, E.L. (eds.) PERSUASIVE 2012. LNCS, vol. 7284, pp. 1-12. Springer, Heidelberg (2012)

19. Lampe, C., Wash, R., Velasquez, A., Ozkaya, E.: Motivations to Participate in Online Communities. In: Proc. CHI 2010, pp. 1927-1936. ACM Press (2010) 
20. Li, I., Dey, A.K., Forlizzi, J.: Using Context to Reveal Factors that Affect Physical Activity. ACM Trans. Comput.-Hum. Interact. 19, 7:1-7:21 (2012)

21. Lin, J.J., Mamykina, L., Lindtner, S., Delajoux, G., Strub, H.B.: Fish'n'Steps: Encouraging Physical Activity with an Interactive Computer Game. In: Dourish, P., Friday, A. (eds.) UbiComp 2006. LNCS, vol. 4206, pp. 261-278. Springer, Heidelberg (2006)

22. Lloyd-Jones, D., Adams, R.J., Brown, T.M., Carnethon, M., Dai, S., Wylie-Rosett, J.: Heart Disease and Stroke Statistics-2010 Update. Circulation 121, e46-e215 (2010)

23. Madan, A., Moturu, S.: t., Lazer, D., and Pentland, A.S.: Social Sensing: Obesity, Unhealthy Eating and Exercise in Face-to-Face Networks. In: Proc. Wireless Health 2010, pp. 104-110 (2010)

24. Maitland, J., Chalmers, M.: Designing for Peer Involvement in Weight Management. In: Proc. CHI 2011, pp. 315-324. ACM Press (2011)

25. Maloney-Krichmar, D., Preece, J.: A Multilevel Analysis of Sociability, Usability, and Community Dynamics in an Online Health Community. ACM Trans. on Comput.-Hum. Interaction 12, 201-232 (2005)

26. Mamykina, L., Miller, A.D., Mynatt, E.D., Greenblatt, D.: Constructing Identities Through Storytelling in Diabetes Management. In: Proc. CHI 2010, pp. 477-486. ACM Press (2010)

27. Mamykina, L., Mynatt, E.D., Davidson, P.R., Greenblatt, D.: MAHI: Investigation of Social Scaffolding for Reflective Thinking in Diabetes Management. In: Proc. CHI 2010, pp. 477-486. ACM Press (2008)

28. McQuail, D.: The Rise of Media of Mass Communication. In: McQuail, D. (ed.) Mass Communication Theory: An Introduction, pp. 1-29 (1994)

29. Newman, M.W., Lauterback, D., Munson, S.A., Resnick, P., Morris, M.E.: It's Not That I Don't Have Problems, I'm Just Not Putting Them On Facebook: Challenges and Opportunities in Using Online Social Networks for Health. In: Proc. CSCW 2011, pp. 341-350. ACM Press (2010)

30. Papacharissi, Z., Rubin, A.M.: Predictors of Internet Use. J. Broadcast. Electron. 44, 341350 (2000)

31. Pate, R.R., Pratt, M., Blair, S.N., Haskell, W.L., Macera, C.A., Wilmore, J.H.: Physical Activity and Public Health: A Recommendation from the Centers for Disease Control and Prevention and the American College of Sports Medicine. J. Am. Med. Assoc. 273, 402407 (1995)

32. Prochaska, J.O., Velicer, W.F.: The Transtheoretical Model of health Behavior Change. Am. J. Health Promot. 12, 38-48 (1997)

33. Purpura, S., Schwanda, V., Williams, K., Stubler, W., Sengers, P.: Fit4Life: The Design of a Persuasive Technology Promoting Healthy Behavior and Ideal Weight. In: Proc. CHI 2011, pp. 423-432. ACM Press (2011)

34. Richardson, C.R., Buis, L.R., Janney, A.W., Goodrich, D.E., Sen, A., Hess, M.L., Mehari, K.S., Fortlage, L.A., Resnick, P.J., Strecher, R.J.Z., Piette, J.D.: An Online Community Improves Adherence in an Internet-Mediated Walking Program. Part 1: Results of a Randomized Controll Trial. JMIR 12, e71 (2010)

35. Ruggiero, T.E.: Uses and Gratification Theory in the 21 st Century. Mass Commun. Soc. 3 , 3-31 (2000)

36. Sillence, E., Briggs, P., Harris, P.R., Fishwick, L.: How do Patients Evaluate and Make Use of Online Health Information? Soc. Sci. Med. 64, 1853-1862 (2007)

37. Toscos, T., Faber, A., An, S., Gandhi, M.P.: Chick Clique: Persuasive Technology to Motivate Teenage Girl to Exercise. In: Ext. Abstracts CHI 2006, pp. 1873-1878. ACM Press (2006) 